\title{
DETERIORAÇÃO DE SEMENTES DE ESPÉCIES BRASILEIRAS DE EUGENIA EM FUNÇÃO DA INCIDÊNCIA E DO CONTROLE DE FUNGOS ${ }^{1}$
}

\author{
CAROLINA FERNANDES DE OLIVEIRA², DENISE CARDOSO DE OLIVEIRA ${ }^{3}$, \\ JOÃO JOSÉ DIAS PARISI ${ }^{4}$, CLAUDIO JOSÉ BARBEDO ${ }^{5}$
}

\begin{abstract}
RESUMO - A conservação de sementes intolerantes à dessecação como as do gênero Eugenia é realizada com alto grau de umidade, favorecendo o ataque de microrganismos. Essa interação da semente com fungos de armazenamento pode acelerar consideravelmente a velocidade de deterioração das mesmas. $\mathrm{O}$ tratamento com fungicidas pode contaminar o meio ambiente com resíduos tóxicos, tornando necessário o desenvolvimento de métodos alternativos como os tratamentos térmicos e osmóticos. No presente trabalho, objetivou-se analisar a influência da redução do teor de água e a eficiência de tratamentos térmicos (imersão das sementes em água, de $35{ }^{\circ} \mathrm{C}$ a $75{ }^{\circ} \mathrm{C}$, por 30 a 150 min), osmóticos (imersão contínua em solução osmótica a $-1,5$ MPa a -4,0 MPa) e químicos (fungicidas carboxin+tiram, captan e carbendazin+tiram) na redução do potencial de inóculo inicial de fungos. Os tratamentos químicos foram os mais eficientes para o controle de Penicillium sp., Cladosporium sp., Fusarium sp., Pestalotiopsis sp. e Alternaria sp., detectados com mais frequência em sementes de Eugenia brasiliensis (grumixameira), E. pyrifomis (uvaieira) e E. uniflora (pitangueira). Tratamentos térmicos e osmóticos demonstram grande potencial de controle, mas necessitam ajustes metodológicos, incluindo-se a associação de ambos e a reaplicação dos tratamentos durante o armazenamento.
\end{abstract}

Termos para indexação: espécie nativa, sementes tropicais, tratamento de sementes.

\section{INCIDENCE AND CONTROL OF FUNGI ASSOCIATED WITH SEEDS OF BRAZILIAN EUGENIA SPECIES}

\begin{abstract}
Seeds intolerant to desiccation, such as those from Eugenia species, must be stored with a high water content which can contribute to microorganism development and lead to rapid seed deterioration. However, normal chemical control is unsuitable considering the use of these seeds in the natural environment. Thermal (seeds in water at $35^{\circ} \mathrm{C}$ to $75{ }^{\circ} \mathrm{C} / 30$ to $150 \mathrm{~min}$ ) and osmotic (seeds stored in an osmotic solution varying from $-1,5 \mathrm{MPa}$ to $-4,0 \mathrm{MPa}$ ) treatments, as well as controlled drying, could be used but there is little information about them and this gave origin to the present study. Results showed that chemical treatments (carboxin+thiram, captan and
\end{abstract}

${ }^{1}$ Submetido em 25/08/2010. Aceito para publicação em 22/02/2011. Parte da Dissertação de Mestrado do primeiro autor apresentada ao Programa de Pós-Graduação em Biodiversidade Vegetal e Meio Ambiente do Instituto de Botânica (IBt), SP. Apoio financeiro: CNPq (Processos 477640/2009-5 e 308045/2007-6) e FAPESP (Processo 2005/04139-7).

${ }^{2}$ Bióloga, Pós-Graduanda do Núcleo de Pesquisa em Sementes, IBt, Av. Miguel Stéfano 3687, 04301-012 São Paulo, SP, catu_fernandes@ hotmail.com.
${ }^{3}$ Bióloga, ex-estagiária de iniciação científica (PIBIC/CNPq) do Núcleo de Pesquisa em Sementes, IBt, denacardoso@uol.com.br.

${ }^{4}$ Eng. Agr., MSc., Centro de Pesquisa e Desenvolvimento de Fitossanidade do Instituto Agronômico (IAC), Av. Barão de Itapura 1481,13020-433, Campinas, SP, jparisi@iac.sp.gov.br.

${ }^{5}$ Eng. Agr., Dr, Núcleo de Pesquisa em Sementes, IBt, claudio.barbedo@, pesquisador.cnpq.br, bolsista CNPq. Autor para correspondência. 
carbendazim+thiram) were the most efficient for controlling the most frequent fungal species, including Penicillium sp., Cladosporium sp., Fusarium sp., Pestalotiopsis sp. and Alternaria sp. in seeds of Eugenia brasiliensis ("grumixameira"), E. uniflora ("pitangueira") and E. pyriformis ("uvaieira"). Thermal and osmotic treatments show significant potential for the control of these fungi but specific methodology must be developed, considering the inter-relationships of these treatments and the need to make successive application during seed storage.

Index terms: native species, seed treatment, tropical seeds.

\section{INTRODUÇÃO}

A conservação de sementes tem utilizado como principal técnica de preservação da sua qualidade fisiológica a redução do metabolismo durante o armazenamento, por meio da remoção da água ou da diminuição da temperatura (Barbedo e Bilia, 1998; Angelovici et al., 2010). Contudo, essa técnica pode ser empregada apenas para as sementes denominadas ortodoxas, ou seja, aquelas que podem ser desidratadas a baixos teores de água (Roberts, 1973).

Para as sementes denominadas recalcitrantes, que não toleram desidratação e baixas temperaturas, perdendo a viabilidade rapidamente quando o teor de água é diminuído para valores inferiores a aproximadamente $30 \%$, há necessidade do desenvolvimento de novas técnicas (Barbedo e Marcos Filho, 1998). Várias espécies tropicais, principalmente nativas do Brasil, produzem sementes intolerantes à dessecação aos níveis desejáveis para a conservação em armazenamento, como no caso das espécies com sementes recalcitrantes do gênero Eugenia, da família Myrtaceae (Kohama et al., 2006).

Eugenia contempla espécies com valor comercial, nutritivo, com potencial de aproveitamento na obtenção de fármacos (Donadio, 1997; Silva et al., 2003) e na recomposição vegetal, por meio do enriquecimento do habitat com a fauna para o equilíbrio biológico e ecológico, além de sua qualidade ornamental (Lorenzi, 1992). Grumixameira (E. brasiliensis Lam.), pitangueira (E. uniflora Lam.) e uvaieira (E. pyriformis Camb.) foram domesticadas e já vêm sendo cultivadas desde árvores isoladas em residências até pomares comerciais. As sementes dessas espécies apresentam limites de secagem bastante elevados (Delgado e Barbedo, 2007). Devido a essa alta suscetibilidade à perda de água, o armazenamento é realizado com sementes de elevado grau de umidade, favorecendo o ataque de microrganismos e a germinação indesejada das sementes ainda durante o armazenamento (Vieira et al., 2001). Essa interação da semente com fungos de armazenamento pode acelerar consideravelmente a velocidade de deterioração das mesmas (Marcos Filho, 2004). Fungos como Penicillium sp. e Aspergillus sp., por exemplo, desenvolvem-se rapidamente, levando à redução da viabilidade das sementes, como observado em amendoim bravo (Nascimento et al., 2006).

Uma das maneiras de controlar esses fungos é o tratamento de sementes com fungicidas, tais como carbendazin, carboxin, captan, thiabendazole e thiram (Krugner e Auer, 2005), mas pode ocorrer contaminação do ambiente com resíduos tóxicos e aumento na resistência dos microrganismos a esses compostos. Métodos alternativos, como o tratamento térmico, podem produzir bons resultados (Nameth, 1998), mas, isoladamente, podem não ser suficientemente eficientes. O tratamento térmico consiste em colocar as sementes em contato com o calor, para que os patógenos presentes sejam eliminados sem perda da germinação e vigor e podem ser baseados em imersão em água quente, ar quente e seco, vapor arejado e energia solar (Menten, 1991).

O condicionamento osmótico, mantendo-se as sementes em soluções osmóticas com potencial hídrico previamente estabelecido, poderia constituir método alternativo, mas pouco foi estudado. Esse condicionamento mostrou potencial para ampliar a capacidade de armazenamento das sementes recalcitrantes, provavelmente reduzindo o metabolismo intenso e desordenado das sementes como resultado da regulação da mobilização da água na semente (Andréo et al., 2006). Esse condicionamento poderia ser utilizado, também, para diminuir a disponibilidade hídrica para os fungos, limitando o desenvolvimento dos mesmos antes de causar prejuízos às sementes.

No presente trabalho objetivou-se analisar a incidência 
fúngica e a influência do teor de água das sementes de grumixameira, pitangueira e uvaieira, bem como a eficiência de tratamentos térmicos, osmóticos e químicos, na redução do potencial de inóculo inicial desses fungos, visando à ampliação da capacidade de conservação da viabilidade dessas sementes durante o armazenamento.

\section{MATERIAL E MÉTODOS}

Frutos de uvaieira, pitangueira e grumixameira foram coletados em matrizes plantadas no Jardim Botânico

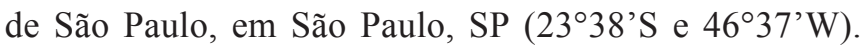
$\mathrm{O}$ processo de extração e beneficiamento de sementes consistiu da retirada manual da polpa, eliminação de sementes danificadas por insetos ou imaturas e armazenamento em sacos de polietileno, em câmara fria ( $8{ }^{\circ} \mathrm{C}$, conforme indicado por Kohama et al., 2006), até a instalação dos experimentos, não ultrapassando 15 dias.

As sementes das três espécies foram submetidas à secagem e aos tratamentos térmico, osmótico e químico, conforme descrito adiante. Após a aplicação dos tratamentos, as sementes foram analisadas quanto ao teor de água, gravimetricamente $\left(103{ }^{\circ} \mathrm{C}\right.$ por $17 \mathrm{~h}$ - ISTA, 1985), ao comportamento germinativo e à qualidade sanitária. O teste de germinação foi conduzido em rolos de papel Germitest, previamente umedecidos (Brasil, 1992), mantidos em germinadores Marconi MA400, regulados para $25^{\circ} \mathrm{C}$, com luz contínua e $100 \%$ de umidade relativa do ar, garantida pela circulação interna de água no sistema de cortina. As avaliações foram realizadas a cada 7 dias durante 60 dias (Silva et al., 2003; Kohama et al., 2006; Delgado e Barbedo, 2007).

A avaliação da microflora das sementes foi realizada pelo método de incubação em papel de filtro (Brasil, 1992). As sementes foram distribuídas equidistantemente em placas de Petri, contendo três folhas de papel de filtro umedecidas com água destilada, incubadas por sete dias a $20 \pm 2{ }^{\circ} \mathrm{C}$ e luz direta. A identificação e contagem dos fungos foram realizadas examinando-se as colônias fúngicas desenvolvidas nas sementes com auxílio de microscópio estereoscópico. Em alguns casos, a identificação foi complementada pela visualização das características morfológicas dos fungos em microscópio óptico (Barnett e Hunter, 1999).

\section{Secagem, tratamento com fungicida e armazenamento das sementes:}

Para analisar a influência da redução do teor de água das sementes na viabilidade ao longo do armazenamento e no controle dos fungos incidentes, as sementes foram submetidas à secagem intermitente em estufa com circulação forçada de ar, regulada para $40{ }^{\circ} \mathrm{C}$, até atingirem os níveis pré-crítico (abaixo do qual se inicia a redução do vigor da semente) e pré-letal (abaixo do qual a semente perde completamente a viabilidade), baseandose em informações de Delgado e Barbedo (2007). Foram realizados ciclos de oito horas de secagem por 16 horas de repouso, este último em sacos plásticos de polietileno ( 8 $\left.{ }^{\circ} \mathrm{C}\right)$. Dessa maneira, foram determinados três tratamentos de secagem: sementes sem secagem (ou seja, com o teor de água original), secagem pré-crítica e secagem préletal.

Após as secagens, as sementes de cada um desses três tratamentos foram divididas em dois grupos, um dos quais recebeu tratamento com o fungicida carboxin + tiram (Vitavax-Thiram 200SC), de ação sistêmica e de contato, na proporção de $300 \mathrm{ml}$ de fungicida para cada $100 \mathrm{~kg}$ de semente, segundo recomendações do fabricante para o tratamento de sementes de espécies cultivadas. Assim que tratadas e após 90 e 180 dias de armazenamento em sacos de polietileno, em câmara fria $\left(8^{\circ} \mathrm{C}\right)$, essas sementes foram avaliadas novamente quanto ao teor de água, germinação e sanidade, conforme descrito anteriormente. Constituiuse, dessa forma, um experimento fatorial entre secagens $\mathrm{x}$ tratamento fungicida $\mathrm{x}$ período de armazenamento, com $3 \times 2 \times 3$, para sementes de uvaieira e de pitangueira. Em função da baixa disponibilidade de sementes, para grumixameira foram analisados seis tratamentos pela combinação de secagem (sem secagem e secagem pré-crítica), armazenamento (90 dias) e tratamento fungicida. O delineamento, para todos os experimentos, foi inteiramente casualizado, com posterior análise de variância e comparação de médias pelo teste de Tukey, aos 5\% (Santana e Ranal, 2004).

Tratamentos térmico, osmótico e químico e armazenamento das sementes:

Para o tratamento térmico, amostras de sementes foram imersas em água, em béquer de vidro, em estufas reguladas para diferentes temperaturas, por diferentes períodos, nas seguintes associações: (a) para grumixameira: 55 ${ }^{\circ} \mathrm{C} / 30$ min, $55{ }^{\circ} \mathrm{C} / 150$ min, $65{ }^{\circ} \mathrm{C} / 30$ min, $65{ }^{\circ} \mathrm{C} / 150$ min, $75{ }^{\circ} \mathrm{C} / 30 \mathrm{~min}$ e $75{ }^{\circ} \mathrm{C} / 150 \mathrm{~min}$; (b) para pitangueira: $55{ }^{\circ} \mathrm{C} / 90 \mathrm{~min}, 55{ }^{\circ} \mathrm{C} / 120 \mathrm{~min}$ e $65{ }^{\circ} \mathrm{C} / 30 \mathrm{~min}$; (c) para uvaieira: $35{ }^{\circ} \mathrm{C} / 30 \mathrm{~min}, 35{ }^{\circ} \mathrm{C} / 90 \mathrm{~min}, 45{ }^{\circ} \mathrm{C} / 30 \mathrm{~min}, 45$ ${ }^{\circ} \mathrm{C} / 90 \mathrm{~min}, 55{ }^{\circ} \mathrm{C} / 30 \min$ e $55{ }^{\circ} \mathrm{C} / 90 \mathrm{~min}$. Ao término de cada período de exposição aos tratamentos, as sementes foram depositadas sobre papel de filtro, à temperatura 
ambiente, para retirada do excesso de água superficial.

Para o tratamento osmótico, amostras de sementes foram armazenadas em caixas tipo gerbox, com uma folha de papel de filtro grosso na base e uma para cobertura, contendo soluções de polietilenoglicol (PEG 6000) com os seguintes potenciais hídricos: (a) para grumixameira e pitangueira: -4,0 MPa; (b) para uvaieira: -1,5 MPa e -2,5 MPa.

As soluções foram preparadas baseando-se em concentrações e temperaturas descritas por Michel e Kauffmann (1973), aferidas em equipamento WP4, Decagon (Pullmann, USA), com base na temperatura do ponto de orvalho (Decagon, 2001). Os potenciais hídricos foram selecionados baseando-se nos níveis de tolerância à dessecação dessas sementes (Delgado e Barbedo, 2007).

Para o tratamento químico, foram utilizados dois fungicidas, nas doses recomendadas pelos fabricantes para sementes de espécies cultivadas: captan (Captan 750 TS, na dose de $200 \mathrm{~g} / 100 \mathrm{~kg}$ de sementes), com ação apenas de contato e carbendazim + tiram (Derosal Plus, na dose de $300 \mathrm{ml} / 100 \mathrm{~kg}$ de sementes), com ação de contato e sistêmica.

Assim que tratadas e após 60 e 120 dias de armazenamento, as sementes foram avaliadas quanto ao teor de água, germinação e sanidade, conforme descrito anteriormente. Constituiu-se, dessa forma, um experimento fatorial entre tratamentos $\mathrm{x}$ períodos de armazenamento, com 10x2 (grumixameira), 7x3 (pitangueira) e $11 \times 3$ (uvaieira), em delineamento inteiramente casualizado, com posterior análise de variância e comparação de médias pelo teste de Tukey, aos 5\% (Santana e Ranal, 2004).

\section{RESULTADOS E DISCUSSÃO}

\section{Secagem, tratamento com fungicida e armazenamento das sementes:}

A redução do teor de água das sementes de grumixameira de, aproximadamente, 50\% para 35\% (secagem pré-crítica) causou queda na porcentagem de germinação tanto inicialmente quanto após armazenamento por 90 dias (Figura 1A). A redução desses índices foi ainda maior quando o teor de água atingiu aproximadamente $25 \%$ (secagem pré-letal). O tratamento com fungicida praticamente não alterou esse comportamento (Figura 1B), apesar da redução da incidência de alguns fungos como Penicillium sp., Pestalotiopsis sp. e Cladosporium sp. (Tabela 1). Curiosamente, porém, Cladosporium sp. e Botrytis sp. apresentaram elevada incidência após 90 dias de armazenamento apenas nas sementes tratadas com o fungicida. Já a incidência de Penicillium sp., nas sementes tratadas com fungicida, teve grande redução após esse período.

TABELA 1. Fungos associados a sementes de grumixameira (Eugenia brasiliensis) com ou sem secagem (Sec) até o nível pré-crítico, com ou sem tratamento prévio (Fung) com fungicida (Vitavax+Thiram) e antes ou após armazenamento (Armaz) por 90 dias aos $8^{\circ} \mathrm{C}$. Dados em porcentagem.

\begin{tabular}{|c|c|c|c|c|c|c|c|c|}
\hline $\mathrm{Sec}$ & Fung & Armaz & Pnc & Pst & Cld & Fsr & Alt & Btr \\
\hline \multicolumn{9}{|c|}{$\%$} \\
\hline Não & Não & Não & $95 \mathrm{a}$ & $33 a$ & $40 \mathrm{a}$ & $8 \mathrm{a}$ & $3 a$ & $0 \mathrm{~b}$ \\
\hline Não & Não & Sim & $72 a b$ & $7 \mathrm{~b}$ & $0 \mathrm{~b}$ & $15 \mathrm{a}$ & $0 \mathrm{a}$ & $0 \mathrm{~b}$ \\
\hline Não & Sim & Não & $45 \mathrm{bc}$ & $5 \mathrm{~b}$ & $0 \mathrm{~b}$ & $2 \mathrm{a}$ & $0 \mathrm{a}$ & $0 \mathrm{~b}$ \\
\hline Não & Sim & Sim & $25 \mathrm{c}$ & $23 \mathrm{ab}$ & $53 \mathrm{a}$ & $21 \mathrm{a}$ & $3 a$ & $23 \mathrm{a}$ \\
\hline Sim & Não & Não & $95 \mathrm{a}$ & $33 \mathrm{a}$ & $40 \mathrm{a}$ & $8 \mathrm{a}$ & $3 a$ & $0 \mathrm{~b}$ \\
\hline Sim & Não & Sim & $75 \mathrm{ab}$ & $7 \mathrm{~b}$ & $0 \mathrm{~b}$ & $15 \mathrm{a}$ & $0 \mathrm{a}$ & $0 \mathrm{~b}$ \\
\hline
\end{tabular}

Pnc: Penicillium sp.; Pst: Pestalotiopsis sp.; Cld: Cladosporium sp.; Fsr: Fusarium sp.; Alt: Alternaria sp.; Btr: Botrytis sp. Médias seguidas pela mesma letra não diferem entre si (Tukey, $5 \%$ )

A redução do teor de água das sementes de pitangueira de $54 \%$ (sem secagem) para aproximadamente $40 \%$ (secagem pré-crítica) não reduziu a capacidade germinativa inicialmente. Contudo, após 3 e 6 meses de armazenamento a germinação foi reduzida em mais da metade da porcentagem inicial, enquanto as não submetidas à secagem praticamente não sofreram alteração durante o armazenamento (Figura 1C). A redução desse teor para valores próximos aos $27 \%$ (préletal) praticamente eliminou a capacidade germinativa já antes do armazenamento. Marcos Filho (2005) relata que há uma faixa de hidratação na qual há metabolismo 
desordenado, acarretando danos mais acentuados do que os que ocorrem em sementes com teores de água mais elevados. Dessa forma, há limites críticos de hidratação, superiores e inferiores, dentro dos quais as sementes recalcitrantes têm sua longevidade aumentada (Bilia et al, 1999). Portanto, as sementes de pitangueira com teor de água pré-crítico provavelmente atingiram
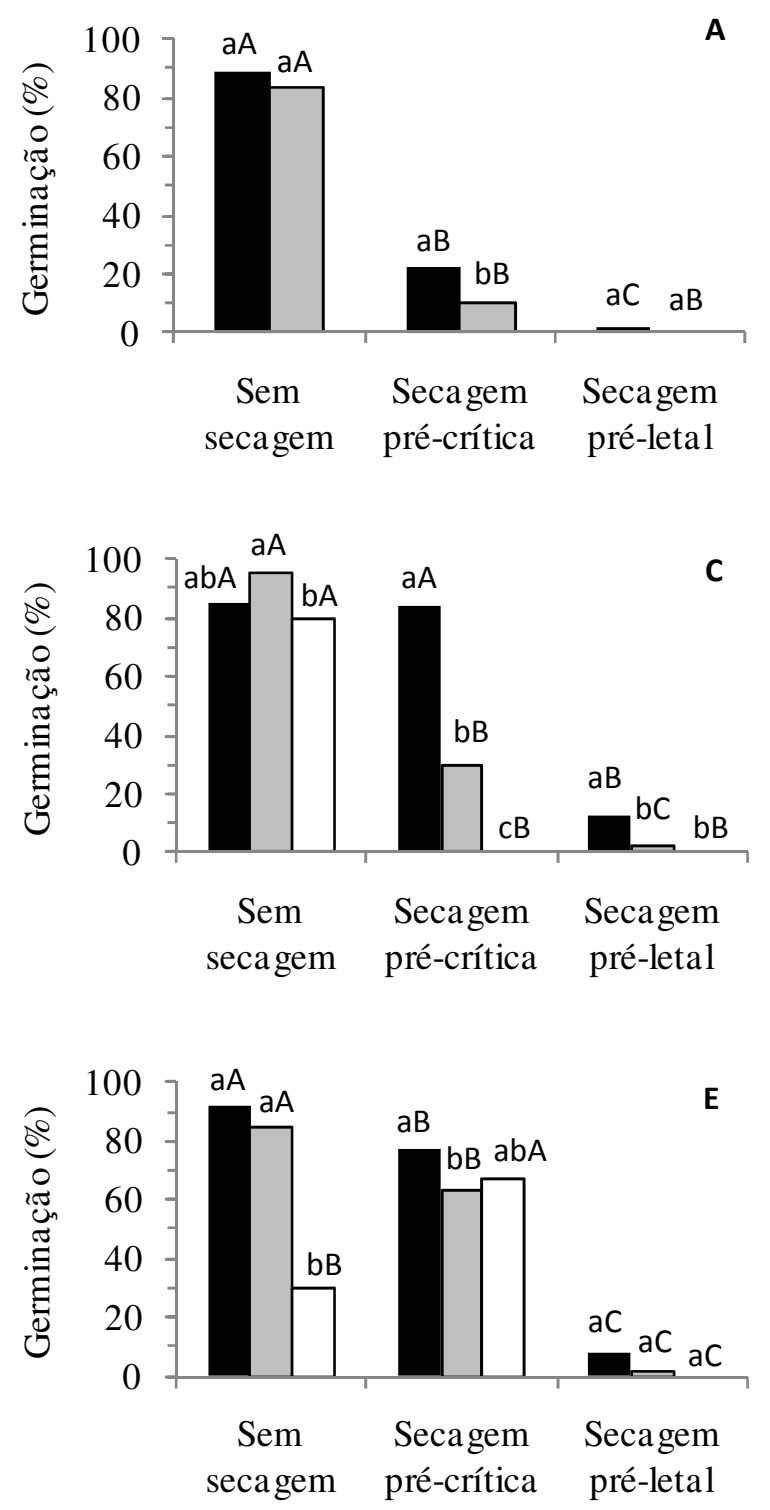

aquela faixa de metabolismo desordenado, reduzindo seu potencial de armazenamento. A ação do fungicida não alterou esse comportamento (Figura 1D) e, embora tenha sido observada redução inicial na incidência da maioria dos fungos detectados, o melhor controle ocorreu associado com a secagem até os níveis préletal e pré-crítico (Tabela 2).
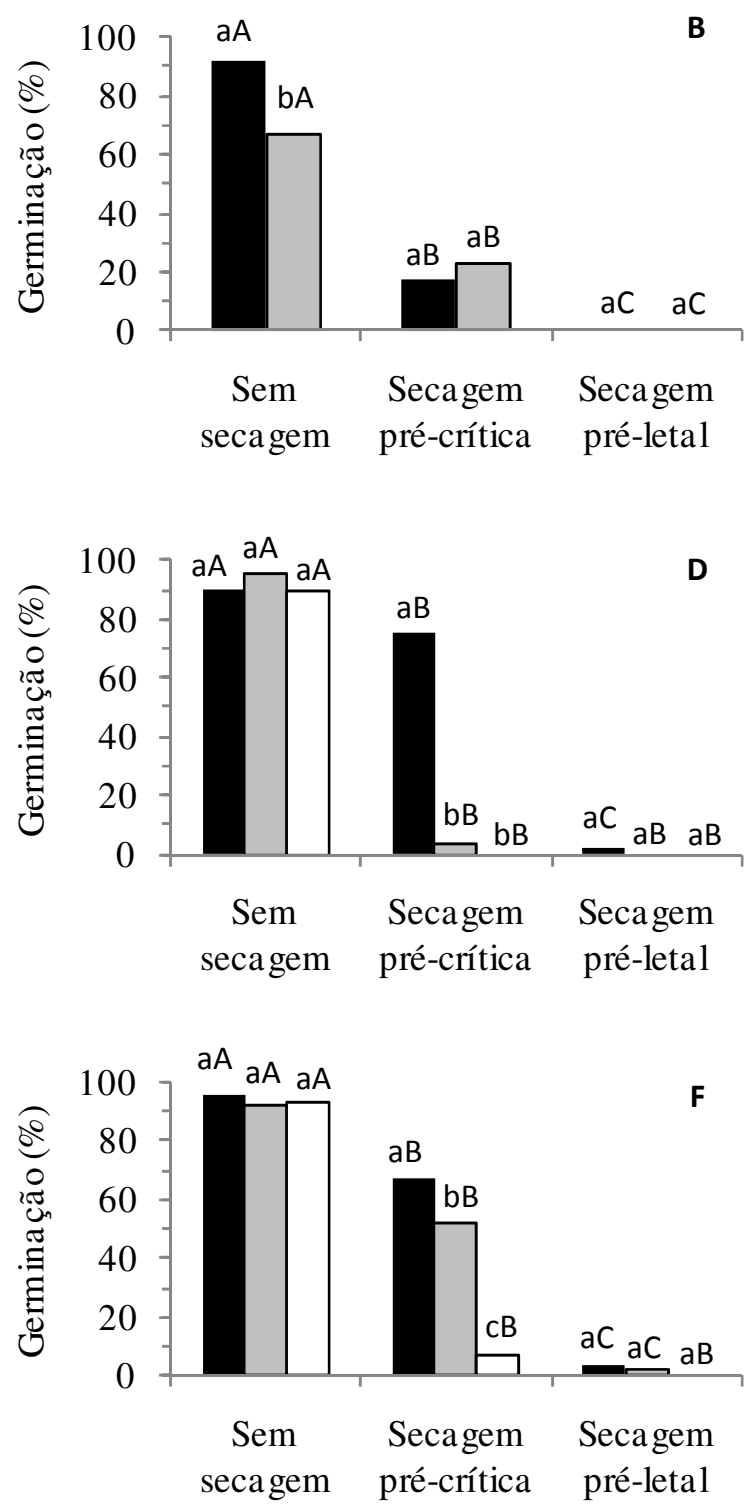

FIGURA 1. Germinação de sementes de grumixameira (A e B), pitangueira (C e D) e uvaieira (E e F), sem (A, C e E) ou com (B, D e F) tratamento fungicida (Vitavax-Thiram 200SC), sem secagem ou submetidas a dois níveis de secagem (pré-crítica e pré-letal) e antes (colunas pretas) ou após armazenamento por 90 (colunas em cinza) e por 180 dias (colunas brancas). Colunas com mesma letra (minúscula para comparações entre períodos de armazenamento, maiúsculas para comparação entre níveis de secagem) não diferem entre si pelo teste de Tukey (5\%). 
TABELA 2. Fungos associados a sementes de pitangueira (Eugenia uniflora) após diferentes níveis de secagem e armazenadas por 90 e 180 dias $\left(8^{\circ} \mathrm{C}\right)$, com ou sem tratamento prévio com Vitavax+Thiram. Dados em porcentagem.

\begin{tabular}{|c|c|c|c|c|c|c|}
\hline \multirow{2}{*}{$\begin{array}{l}\text { Nível de } \\
\text { secagem }\end{array}$} & \multicolumn{3}{|c|}{$\begin{array}{c}\text { Armazenamento (dias) } \\
\text { sem tratamento fungicida }\end{array}$} & \multicolumn{3}{|c|}{$\begin{array}{l}\text { Armazenamento (dias) } \\
\text { com tratamento fungicida }\end{array}$} \\
\hline & Inicial & 90 & 180 & Inicial & 90 & 180 \\
\hline \multicolumn{7}{|c|}{ Penicillium sp. } \\
\hline Sem secagem & $88 \mathrm{aA}$ & $85 \mathrm{aA}$ & $63 \mathrm{aB}$ & $65 \mathrm{aA}$ & $100 \mathrm{aA}$ & $93 \mathrm{aA}$ \\
\hline Pré-crítico & $65 \mathrm{aA}$ & $90 \mathrm{aA}$ & $90 \mathrm{aA}$ & $42 \mathrm{aB}$ & $30 \mathrm{bB}$ & $17 \mathrm{bB}$ \\
\hline Pré-letal & $98 \mathrm{aA}$ & $100 \mathrm{aA}$ & $78 \mathrm{aA}$ & $57 \mathrm{aB}$ & $7 \mathrm{bB}$ & $3 \mathrm{bB}$ \\
\hline \multicolumn{7}{|c|}{ Pestalotiopsis sp. } \\
\hline Sem secagem & $32 \mathrm{aA} a$ & $30 \mathrm{aB} a$ & 43 aA $a$ & $2 \mathrm{aB} c$ & 75 aA $a$ & $53 \mathrm{aA} b$ \\
\hline Pré-crítico & $10 \mathrm{bA} a$ & $3 \mathrm{bA} a$ & $0 \mathrm{bA} a$ & $0 \mathrm{aA} a$ & $0 \mathrm{bA} a$ & $0 \mathrm{bA} a$ \\
\hline Pré-letal & $3 \mathrm{bA} a$ & $12 \mathrm{bA} a$ & $0 \mathrm{bA} a$ & $2 \mathrm{aA} a$ & $0 \mathrm{bA} a$ & $0 \mathrm{bA} a$ \\
\hline \multicolumn{7}{|c|}{ Cladosporium sp. } \\
\hline Sem secagem & $47 \mathrm{bA} b$ & $17 \mathrm{bAc}$ & $75 \mathrm{aA} a$ & $2 \mathrm{aB} b$ & $22 \mathrm{aA} a$ & $0 \mathrm{aB} b$ \\
\hline Pré-crítico & $92 \mathrm{aA} a$ & $67 \mathrm{aA} b$ & $65 \mathrm{aA} b$ & $0 \mathrm{aB} a$ & $0 \mathrm{bB} a$ & $0 \mathrm{aB} a$ \\
\hline Pré-letal & $20 \mathrm{cA} a b$ & $30 \mathrm{bA} a$ & $7 \mathrm{aA} b$ & $2 \mathrm{aB} a$ & $0 \mathrm{bB} a$ & $0 \mathrm{aA} a$ \\
\hline \multicolumn{7}{|c|}{ Fusarium sp. } \\
\hline Sem secagem & $3 \mathrm{aB} b$ & $18 \mathrm{bA} a$ & $17 \mathrm{bB} a$ & $47 \mathrm{aA} a$ & $7 \mathrm{aB} c$ & $28 \mathrm{aA} b$ \\
\hline Pré-crítico & $0 \mathrm{aA} b$ & $13 \mathrm{bA} a$ & $0 \mathrm{aA} b$ & $0 \mathrm{bA} a$ & $0 \mathrm{aB} a$ & $2 \mathrm{bA} a$ \\
\hline Pré-letal & $17 \mathrm{bA} a b$ & $30 \mathrm{aA} a$ & $3 \mathrm{aA} b$ & $2 \mathrm{bB} a$ & $0 \mathrm{aB} a$ & $0 \mathrm{bA} a$ \\
\hline \multicolumn{7}{|c|}{ Botrytis sp. } \\
\hline Sem secagem & $0 \mathrm{bAc}$ & $55 \mathrm{aA} a$ & $32 \mathrm{aA} b$ & $0 \mathrm{aA} a$ & $18 \mathrm{aB} a$ & $5 \mathrm{aB} a$ \\
\hline Pré-crítico & $47 \mathrm{aA} a$ & $37 \mathrm{aA} a$ & $35 \mathrm{aA} a$ & $0 \mathrm{aB} a$ & $0 \mathrm{bB} a$ & $0 \mathrm{aB} a$ \\
\hline Pré-letal & $50 \mathrm{aA} a$ & $7 \mathrm{bA} b$ & $0 \mathrm{bA} b$ & $0 \mathrm{aB} a$ & $0 \mathrm{bA} a$ & $0 \mathrm{aA} a$ \\
\hline
\end{tabular}

Médias seguidas pela mesma letra (minúsculas para comparação entre secagens, maiúsculas entre tratamentos fungicidas e itálicos entre períodos de armazenamento) não diferem entre si (Tukey, $5 \%$ ).

Castellani et al. (1996) relataram que a presença de fungos pode reduzir a capacidade germinativa de um lote de sementes e apresentar problemas, por exemplo, na interpretação dos resultados dos testes de germinação conduzidos em condições de laboratório. De fato, no presente trabalho, notou-se elevada incidência de fungos nas sementes de pitangueira não tratadas, dificultando a avaliação da qualidade fisiológica dos lotes.

Nas sementes de uvaieira (Figura 1E) observouse mesmo comportamento das sementes das espécies anteriores, com relação à germinação, exceto para sementes submetidas à secagem pré-crítica ( $50 \%$ de água) e armazenadas por até 180 dias, que mantiveram elevada porcentagem de germinação. Além disso, o tratamento com fungicida (Figura 1F) permitiu melhor conservação das sementes não submetidas à secagem (65\% de água), mantendo elevados valores de germinação até os 180 dias de armazenamento. Esse resultado pode estar relacionado ao fato de que, diferentemente das espécies anteriores, em uvaieira não se observou o aumento da incidência de Pestalotiopsis sp. e Cladosporium sp. após o armazenamento das sementes tratadas (Tabela 3). 
TABELA 3. Fungos associados a sementes de uvaieira (Eugenia pyriformis) após diferentes níveis de secagem e armazenadas por 90 e 180 dias $\left(8^{\circ} \mathrm{C}\right)$, com ou sem tratamento prévio com Vitavax+Thiram. Dados em porcentagem.

\begin{tabular}{|c|c|c|c|c|c|c|}
\hline \multirow{2}{*}{$\begin{array}{l}\text { Nível de } \\
\text { secagem }\end{array}$} & \multicolumn{3}{|c|}{$\begin{array}{l}\text { Armazenamento (dias) } \\
\text { sem tratamento fungicida }\end{array}$} & \multicolumn{3}{|c|}{$\begin{array}{l}\text { Armazenamento (dias) } \\
\text { com tratamento fungicida }\end{array}$} \\
\hline & Inicial & 90 & 180 & Inicial & 90 & 180 \\
\hline & \multicolumn{6}{|c|}{ Penicillium sp. } \\
\hline Sem secagem & $100 \mathrm{aA} a$ & $100 \mathrm{aA} a$ & $65 \mathrm{abB} b$ & $83 \mathrm{bB} a$ & $60 \mathrm{bB} a$ & $85 \mathrm{bA} a$ \\
\hline Pré-crítico & $98 \mathrm{aA} a$ & $100 \mathrm{aA} a$ & $58 \mathrm{bB} b$ & $97 \mathrm{aA} a$ & $98 \mathrm{aA} a$ & $98 \mathrm{aA} a$ \\
\hline \multirow[t]{2}{*}{ Pré-letal } & $98 \mathrm{aA} a$ & $100 \mathrm{aA} a$ & $99 \mathrm{aA} a$ & $87 \mathrm{bB} a$ & $72 \mathrm{bB} a$ & $83 \mathrm{bB} a$ \\
\hline & \multicolumn{6}{|c|}{ Pestalotiopsis sp. } \\
\hline Sem secagem & $52 \mathrm{aA} a$ & $53 \mathrm{aA} a$ & $65 \mathrm{aA} a$ & $0 \mathrm{bB} a$ & $0 \mathrm{aB} a$ & $12 \mathrm{aB} a$ \\
\hline Pré-crítico & $28 \mathrm{bA} a$ & $13 \mathrm{bA} b$ & $2 \mathrm{bA} b$ & $22 \mathrm{aA} a$ & $3 \mathrm{aA} b$ & $0 \mathrm{aA} b$ \\
\hline \multirow[t]{2}{*}{ Pré-letal } & $25 \mathrm{bA} a$ & $13 \mathrm{bA} a b$ & $3 \mathrm{bA} b$ & $5 \mathrm{bB} a$ & $2 \mathrm{aA} a$ & $0 \mathrm{aA} a$ \\
\hline & \multicolumn{6}{|c|}{ Cladosporium sp. } \\
\hline Sem secagem & $27 \mathrm{bA} b$ & $20 \mathrm{bA} b$ & $67 \mathrm{aA} a$ & $10 \mathrm{bA} a$ & $3 \mathrm{aA} a$ & $0 \mathrm{aB} a$ \\
\hline Pré-crítico & $87 \mathrm{aA} a$ & $42 \mathrm{bA} b$ & $43 \mathrm{bA} b$ & $63 \mathrm{aB} a$ & $0 \mathrm{aB} b$ & $0 \mathrm{aB} b$ \\
\hline \multirow[t]{2}{*}{ Pré-letal } & $83 \mathrm{aA} a$ & $73 \mathrm{aA} a$ & $70 \mathrm{aA} a$ & $8 \mathrm{bB} a$ & $3 \mathrm{aB} a$ & $0 \mathrm{aB} a$ \\
\hline & \multicolumn{6}{|c|}{ Fusarium sp. } \\
\hline Sem secagem & $3 \mathrm{bAc}$ & $32 \mathrm{aA} b$ & $68 \mathrm{aA} a$ & $0 \mathrm{bA} b$ & $10 \mathrm{cB} b$ & $48 \mathrm{bB} a$ \\
\hline Pré-crítico & $2 \mathrm{aB} c$ & $35 \mathrm{aB} b$ & $80 \mathrm{aA} a$ & $0 \mathrm{bA} b$ & $73 \mathrm{aA} a$ & $92 \mathrm{aA} a$ \\
\hline Pré-letal & $37 \mathrm{aB} a b$ & $50 \mathrm{aA} a$ & $25 \mathrm{bA} b$ & 73 aA $a$ & $35 \mathrm{bA} b$ & $3 \mathrm{cB} c$ \\
\hline
\end{tabular}

Médias seguidas pela mesma letra (minúsculas para comparação entre secagens, maiúsculas entre tratamentos fungicidas e itálicos entre períodos de armazenamento) não diferem entre si (Tukey, 5\%).

Considerando os dados apresentados é possível constatar que nas sementes recalcitrantes das espécies estudadas o fungo que apresentou inicialmente maior incidência foi Penicillium sp., diferindo do que ocorre nas sementes da maioria das espécies cultivadas (ortodoxas), para as quais esse fungo ocorre mais frequentemente no final do período de armazenamento. A incidência da maioria dos fungos associados a sementes das três espécies de Eugenia diminuiu com o tratamento fungicida, mas a redução foi mais sutil para Penicillium sp. Para Fusarium sp., Pestalotiopsis sp. e Cladosporium sp. a incidência diminuiu mais acentuadamente quando submetidas à secagem. O efeito do controle inicial dos fungos sobre a capacidade de armazenamento das sementes somente ocorreu para uvaieira, a única das espécies estudadas que apresentou redução na germinação após o maior período de armazenamento (Figura 1E). Essa melhora na armazenabilidade ocorreu, também, com a secagem pré-crítica. Contudo, a associação dos dois tratamentos (secagem + fungicida) não foi eficiente, possivelmente devido a um efeito fitotóxico (Figura 1F) que tem ocorrido principalmente com o tempo de secagem e armazenabilidade das sementes tratadas.

Tratamentos térmico, osmótico e químico e armazenamento das sementes:

O teor de água das sementes das espécies estudadas foi bastante elevado, entre $48 \%$ e $69 \%$. Essa elevada umidade poderia favorecer a presença de patógenos (Netto e Faiad, 1995) e, consequentemente, prejudicar a germinação, como foi observado por Andrade e Ferreira (2000) em relação a Aspergillus sp. e Penicillium sp. em sementes de uvaia. As porcentagens de germinação das sementes de grumixameira, contudo, foram muito elevadas mesmo após o armazenamento por 60 dias (Figura 2A), ocorrendo um aumento expressivo na incidência de Cladosporium sp. após 120 dias, enquanto os demais fungos, Penicillium sp. e Pestalotiopsis sp., mantiveram incidências próximas às iniciais (Tabela 4 ). A imersão dessas sementes em água em $65{ }^{\circ} \mathrm{C}$ durante 150 minutos promoveu decréscimo na germinação e, em 
$75{ }^{\circ} \mathrm{C}$, eliminou a capacidade germinativa (Figura 2A), permitindo maior crescimento de Penicillium sp. (Tabela 4). O tratamento térmico aos $65^{\circ} \mathrm{C}$ durante 30 minutos não afetou a germinação (Figura 2A), mas apresentou baixa eficiência no controle de Cladosporium sp. e de Pestalotiopsis sp. e aumento na incidência de Penicillium sp. (Tabela 4). Esses tratamentos permitem supor que é possível utilizar o tratamento térmico para essa espécie até a temperatura de $65^{\circ} \mathrm{C}$, mas períodos mais extensos de exposição devem ser explorados. Os aumentos na incidência de Cladosporium sp. e Pestalotiopsis sp. após o armazenamento, principalmente nos tratamentos em $75{ }^{\circ} \mathrm{C}$, provavelmente deveram-se ao fato das sementes estarem mortas.

A germinação inicial de sementes de pitangueira foi mais baixa que a observada após 60 dias de armazenamento (Figura 2B). Curiosamente, esse aumento coincidiu com a redução na incidência de Penicillium sp. (Tabela 5), sugerindo alguma interferência desse fungo no próprio teste de germinação. De acordo com Machado (1988), este fungo pode ocasionar a perda do poder germinativo e, durante o armazenamento, promover o aquecimento da massa de sementes com consequente aumento da taxa respiratória, provocando a deterioração mais rápida das sementes. Os tratamentos térmicos pouco alteraram os valores de germinação (Figura 2B), mas aumentaram a incidência de Penicillium sp. nas sementes; diferentemente da testemunha, porém, essa incidência permaneceu elevada durante $o$ armazenamento (Tabela 5). Dentre os fungos identificados colonizando as sementes de pitangueira, destacaram-se Alternaria sp., Cladosporium sp. e Penicillium sp. (Tabela 5). No caso do Alternaria sp., todos os tratamentos foram eficazes na sua erradicação das sementes, tendo apenas as sementes do tratamento controle sido colonizadas no início e ao longo do armazenamento. Em relação a Cladosporium sp., sua incidência aumentou ao longo do armazenamento, sendo os tratamentos químicos e osmóticos os únicos eficientes em seu controle. Contudo, de acordo com von Bülow et al. (1994), a alta incidência de fungos saprófitas encontrados nas sementes de pitanga-vermelha-do-cerrado (espécie pertencente ao mesmo gênero das estudadas no presente trabalho) não prejudicou a germinação. Esses resultados demonstram a potencialidade do tratamento osmótico. Um melhor ajuste no potencial hídrico da solução do tratamento osmótico, contudo, ainda é necessária, uma vez que houve redução nos valores de germinação, para esse tratamento, ao longo do armazenamento (Figura 2B).
TABELA 4. Valores correspondentes a incidência de Cladosporium sp.,Penicillium sp. e Pestalotiopsis sp. em sementes de grumixameira em função do tratamento e do período de armazenamento. Dados em porcentagem.

\begin{tabular}{|c|c|c|c|}
\hline \multirow{2}{*}{ Tratamentos } & \multicolumn{3}{|c|}{ Armazenamento (dias) } \\
\hline & 0 & 60 & 120 \\
\hline & \multicolumn{3}{|c|}{ Cladosporium sp. } \\
\hline Testemunha & $2 \mathrm{aB}$ & $16 \mathrm{abcB}$ & $31 \mathrm{bcA}$ \\
\hline $55^{\circ} \mathrm{C} / 30 \mathrm{~min}$ & $0 \mathrm{aA}$ & $2 \mathrm{bcA}$ & $11 \mathrm{de} A$ \\
\hline $55^{\circ} \mathrm{C} / 150 \mathrm{~min}$ & $0 \mathrm{aB}$ & $15 \mathrm{abcA}$ & $7 \mathrm{de} A B$ \\
\hline $65^{\circ} \mathrm{C} / 30 \mathrm{~min}$ & $2 \mathrm{aB}$ & $9 \mathrm{bcB}$ & $49 \mathrm{bA}$ \\
\hline $65^{\circ} \mathrm{C} / 150 \mathrm{~min}$ & $0 \mathrm{aB}$ & $31 \mathrm{aA}$ & $21 \mathrm{cdA}$ \\
\hline $75^{\circ} \mathrm{C} / 30 \mathrm{~min}$ & $2 \mathrm{aC}$ & $20 \mathrm{abB}$ & $71 \mathrm{aA}$ \\
\hline $75^{\circ} \mathrm{C} / 150 \mathrm{~min}$ & $0 \mathrm{aB}$ & $0 \mathrm{cB}$ & $38 \mathrm{bcA}$ \\
\hline$-4,0 \mathrm{MPa}$ & $2 \mathrm{aA}$ & $0 \mathrm{cA}$ & $0 \mathrm{eA}$ \\
\hline Captan & $0 \mathrm{aA}$ & $0 \mathrm{cA}$ & $0 \mathrm{eA}$ \\
\hline \multirow[t]{2}{*}{ Derosal } & $2 \mathrm{aA}$ & $0 \mathrm{cA}$ & $0 \mathrm{eA}$ \\
\hline & \multicolumn{3}{|c|}{ Penicillium sp. } \\
\hline Testemunha & $11 \mathrm{dA}$ & $4 \mathrm{bA}$ & $2 \mathrm{dA}$ \\
\hline $55^{\circ} \mathrm{C} / 30 \mathrm{~min}$ & $4 \mathrm{dA}$ & $9 \mathrm{bA}$ & $2 \mathrm{dA}$ \\
\hline $55^{\circ} \mathrm{C} / 150 \mathrm{~min}$ & $51 \mathrm{bcA}$ & $56 \mathrm{aA}$ & $22 \mathrm{cdB}$ \\
\hline $65^{\circ} \mathrm{C} / 30 \mathrm{~min}$ & $42 \mathrm{cB}$ & $71 \mathrm{aA}$ & $58 \mathrm{abAB}$ \\
\hline $65^{\circ} \mathrm{C} / 150 \mathrm{~min}$ & $89 \mathrm{aA}$ & $49 \mathrm{aB}$ & $56 \mathrm{abB}$ \\
\hline $75^{\circ} \mathrm{C} / 30 \mathrm{~min}$ & $49 \mathrm{bcB}$ & $73 \mathrm{aA}$ & $40 \mathrm{bcB}$ \\
\hline $75^{\circ} \mathrm{C} / 150 \mathrm{~min}$ & $75 \mathrm{abA}$ & $76 \mathrm{aA}$ & $20 \mathrm{cdB}$ \\
\hline$-4,0 \mathrm{MPa}$ & $2 \mathrm{~dB}$ & $0 \mathrm{bB}$ & $78 \mathrm{aA}$ \\
\hline Captan & $0 \mathrm{dA}$ & $0 \mathrm{bA}$ & $0 \mathrm{dA}$ \\
\hline \multirow[t]{2}{*}{ Derosal } & $0 \mathrm{dA}$ & $0 \mathrm{bA}$ & $0 \mathrm{dA}$ \\
\hline & \multicolumn{3}{|c|}{ Pestalotiopsis sp. } \\
\hline Testemunha & $12 \mathrm{aA}$ & $19 \mathrm{bA}$ & $26 \mathrm{abcA}$ \\
\hline $55^{\circ} \mathrm{C} / 30 \mathrm{~min}$ & $0 \mathrm{aB}$ & $27 \mathrm{bA}$ & $23 \mathrm{abcA}$ \\
\hline $55^{\circ} \mathrm{C} / 150 \mathrm{~min}$ & $0 \mathrm{aB}$ & $9 \mathrm{bcA}$ & $19 \mathrm{abcAB}$ \\
\hline $65^{\circ} \mathrm{C} / 30 \mathrm{~min}$ & $0 \mathrm{aB}$ & $16 \mathrm{bcAB}$ & $28 \mathrm{abA}$ \\
\hline $65^{\circ} \mathrm{C} / 150 \mathrm{~min}$ & $0 \mathrm{aB}$ & $21 \mathrm{bcA}$ & $10 \mathrm{bcAB}$ \\
\hline $75^{\circ} \mathrm{C} / 30 \mathrm{~min}$ & $0 \mathrm{aC}$ & $80 \mathrm{aA}$ & $43 \mathrm{aB}$ \\
\hline $75^{\circ} \mathrm{C} / 150 \mathrm{~min}$ & $0 \mathrm{aB}$ & $5 \mathrm{bcB}$ & $36 \mathrm{aA}$ \\
\hline$-4,0 \mathrm{MPa}$ & $0 \mathrm{aA}$ & $0 \mathrm{cA}$ & $0 \mathrm{cA}$ \\
\hline Captan & $0 \mathrm{aA}$ & $0 \mathrm{cA}$ & $0 \mathrm{cA}$ \\
\hline Derosal & $0 \mathrm{aA}$ & $0 \mathrm{cA}$ & $0 \mathrm{cA}$ \\
\hline
\end{tabular}

Médias seguidas pela mesma letra (minúsculas nas colunas, maiúsculas nas linhas) não diferem entre si (Tukey, 5\%). 


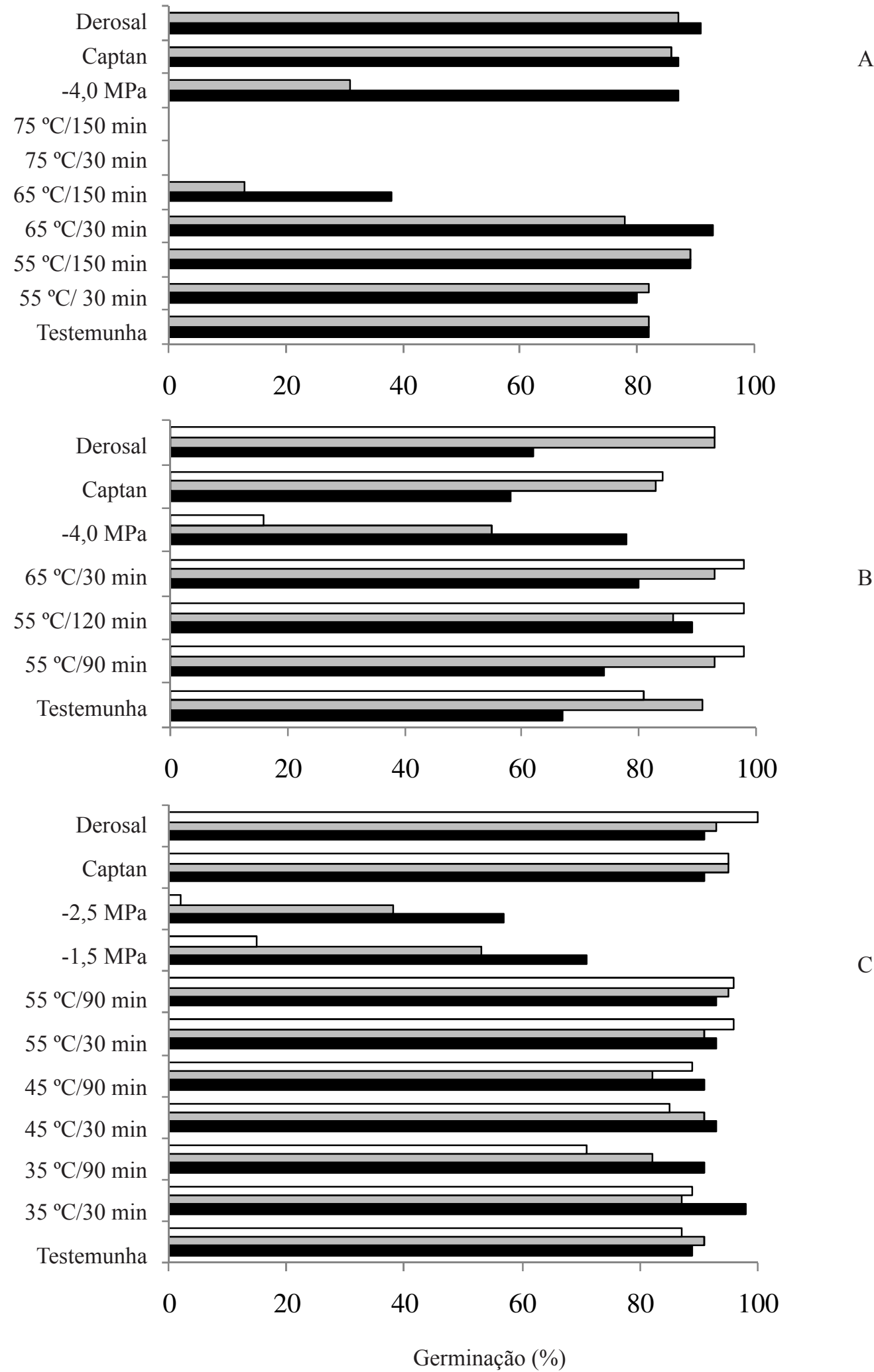

FIGURA 2. Germinação de sementes de grumixameira (A), pitangueira (B) e uvaieira (C) submetidas a tratamentos térmicos, osmóticos e com fungicidas, antes (colunas pretas) ou após armazenamento por 60 (colunas em cinza) e por 120 dias (colunas brancas). 
TABELA 5. Valores correspondentes a incidência de Alternaria sp., Cladosporium sp. e Penicillium sp. em sementes de pitangueira em função do tratamento e do período de armazenamento. Dados em porcentagem.

\begin{tabular}{lccc}
\hline \multirow{2}{*}{ Tratamentos } & \multicolumn{3}{c}{ Armazenamento (dias) } \\
\cline { 2 - 4 } & 0 & 60 & 120 \\
\hline \multicolumn{4}{c}{ Alternaria sp. } \\
\hline Testemunha & $17 \mathrm{aB}$ & $35 \mathrm{aA}$ & $44 \mathrm{aA}$ \\
$55^{\circ} \mathrm{C} / 90 \mathrm{~min}$ & $0 \mathrm{bA}$ & $0 \mathrm{bA}$ & $5 \mathrm{bcA}$ \\
$55^{\circ} \mathrm{C} / 120 \mathrm{~min}$ & $0 \mathrm{bA}$ & $0 \mathrm{bA}$ & $0 \mathrm{cA}$ \\
$65^{\circ} \mathrm{C} / 30$ min & $0 \mathrm{bB}$ & $7 \mathrm{bAB}$ & $14 \mathrm{bA}$ \\
$-4,0 \mathrm{MPa}$ & $0 \mathrm{bA}$ & $0 \mathrm{bA}$ & $0 \mathrm{cA}$ \\
Captan & $0 \mathrm{bA}$ & $0 \mathrm{bA}$ & $0 \mathrm{cA}$ \\
Derosal & $0 \mathrm{bA}$ & $0 \mathrm{bA}$ & $5 \mathrm{bcA}$ \\
\hline & Cladosporium sp. \\
\hline Testemunha & $100 \mathrm{aA}$ & $98 \mathrm{aA}$ & $93 \mathrm{aA}$ \\
$55^{\circ} \mathrm{C} / 90 \mathrm{~min}$ & $21 \mathrm{bB}$ & $81 \mathrm{abA}$ & $81 \mathrm{aA}$ \\
$55^{\circ} \mathrm{C} / 120 \mathrm{~min}$ & $14 \mathrm{bB}$ & $64 \mathrm{bA}$ & $69 \mathrm{aA}$ \\
$65^{\circ} \mathrm{C} / 30$ min & $81 \mathrm{aA}$ & $95 \mathrm{aA}$ & $83 \mathrm{aA}$ \\
$-4,0 \mathrm{MPa}$ & $93 \mathrm{aA}$ & $0 \mathrm{cB}$ & $0 \mathrm{bB}$ \\
Captan & $16 \mathrm{bA}$ & $5 \mathrm{cA}$ & $0 \mathrm{bA}$ \\
Derosal & $2 \mathrm{bA}$ & $5 \mathrm{cA}$ & $0 \mathrm{bA}$ \\
\hline & Penicillium sp. & \\
\hline Testemunha & $33 \mathrm{bA}$ & $2 \mathrm{bB}$ & $0 \mathrm{~dB}$ \\
$55^{\circ} \mathrm{C} / 90 \mathrm{~min}$ & $100 \mathrm{aA}$ & $88 \mathrm{bAB}$ & $67 \mathrm{bB}$ \\
$55^{\circ} \mathrm{C} / 120 \mathrm{~min}$ & $100 \mathrm{aA}$ & $91 \mathrm{aA}$ & $45 \mathrm{bcB}$ \\
$-4,0 \mathrm{MPa} / 30 \mathrm{~min}$ & $93 \mathrm{aA}$ & $64 \mathrm{aB}$ & $21 \mathrm{cdC}$ \\
$\mathrm{Captan}_{\text {Derosal }}$ & $72 \mathrm{aB}$ & $88 \mathrm{aAB}$ & $100 \mathrm{aA}$ \\
\hline & $0 \mathrm{cA}$ & $0 \mathrm{bA}$ & $0 \mathrm{dA}$ \\
& $0 \mathrm{cA}$ & $0 \mathrm{bA}$ & $14 \mathrm{cdA}$ \\
\hline
\end{tabular}

Médias seguidas pela mesma letra (minúsculas nas colunas, maiúsculas nas linhas) não diferem entre si (Tukey, $5 \%$ ).

Os tratamentos osmóticos, por outro lado, reduziram substancialmente a germinação das sementes de uvaieira (Figura 2C). Em todos os demais tratamentos, a germinação permaneceu elevada mesmo após 120 dias de armazenamento. Os tratamentos osmóticos, principalmente a $-2,5 \mathrm{MPa}$, que promoveram baixas porcentagens de germinação após 120 dias de armazenamento, corroboraram Delgado (2006), que descreveu prejuízos às sementes dessa espécie com pequenas reduções do potencial hídrico. As sementes de uvaieira foram as que apresentaram o maior número de gêneros fúngicos, destacando-se Alternaria sp., Cladosporium sp., Fusarium sp., Penicillium sp. e Pestalotiopsis sp. (Tabela 6). O tratamento osmótico a -2,5 $\mathrm{MPa}$, além dos químicos, reduziu eficientemente a incidência de Fusarium sp. mesmo após o armazenamento das sementes de uvaieira, enquanto os demais tratamentos pouco controlaram esse fungo (Tabela 6). Segundo Marcos Filho (2005), pesquisas com hidratação controlada ressaltam a redução da liberação de exsudados durante a embebição e, consequentemente, a menor ocorrência de microrganismos associados às sementes. Dentre os demais tratamentos empregados, a imersão em água aos $55^{\circ} \mathrm{C}$ durante 90 minutos só não foi eficiente no controle de Penicillium sp. e Pestalotiopsis sp. (Tabela 6). A eficiência do tratamento térmico mostrou-se dependente da relação tempo x temperatura para cada espécie, ora para se evitarem danos à germinação, ora para efetivamente controlar os fungos associados às sementes de Eugenia. Tal fato também é verificado para outras espécies, como em sementes de sorgo, para as quais o tratamento térmico em água quente aos $55^{\circ} \mathrm{C}$ durante 10 minutos reduziu em mais de $90 \%$ os fungos Alternaria tenuis, Botrytis sorghicola, Botrytis cinerea, Colletotrichum graminicola, Curvularia lunata, com exceção de Fusarium moniliforme (Masum et al. 2009). Já Mendes et al. (2001) conseguiram reduzir significativamente a incidência de Fusarium oxysporum sem prejudicar a germinação das sementes ao aplicar o tratamento térmico de calor seco aos $60{ }^{\circ} \mathrm{C}$ por 20 e 30 minutos.

Pelos resultados obtidos no presente trabalho podese concluir que o fungicida carbendazin + tiram, apesar de não apresentar registro para espécies florestais, foi o mais eficiente no controle dos fungos, mas tratamentos não químicos, menos prejudiciais ao ambiente, como os térmicos e osmóticos estudados no presente trabalho, demonstraram grande potencial de controle. Deve-se salientar que a redução do teor de água das sementes de Eugenia spp. visando a prolongar o armazenamento não tem se mostrado eficiente (Kohama et al., 2006; Delgado; Barbedo, 2007), o que foi verificado também neste trabalho. Entretanto, o armazenamento de sementes com teor de água elevado favorece a proliferação de fungos que podem reduzir o vigor das sementes, principalmente em longo prazo. 
TABELA 6. Valores correspondentes a incidência de Alternaria sp., Cladosporium sp., Pestalotiopsis sp., Fusarium sp. e Penicillium sp. em sementes de uvaieira em função do tratamento e do período de armazenamento. Dados em porcentagem.

\begin{tabular}{|c|c|c|c|c|}
\hline \multirow{2}{*}{ Tratamentos } & \multicolumn{3}{|c|}{ Período de armazenamento (dias) } & \multirow{2}{*}{ Médias* } \\
\hline & 0 (inicial) & 60 & 120 & \\
\hline & \multicolumn{3}{|c|}{ Alternaria sp. } & Fusarium sp. \\
\hline Testemunha & $0 \mathrm{aB}$ & $41 \mathrm{aA}$ & $55 \mathrm{aA}$ & $22 \mathrm{a}$ \\
\hline $35^{\circ} \mathrm{C} / 30 \mathrm{~min}$ & $10 \mathrm{aB}$ & $31 \mathrm{abA}$ & $38 \mathrm{abA}$ & $22 \mathrm{a}$ \\
\hline $35^{\circ} \mathrm{C} / 90 \mathrm{~min}$ & $9 \mathrm{aB}$ & $34 \mathrm{abA}$ & $30 \mathrm{abcAB}$ & $16 \mathrm{abc}$ \\
\hline $45^{\circ} \mathrm{C} / 30 \mathrm{~min}$ & $7 \mathrm{aB}$ & $39 \mathrm{aA}$ & $27 \mathrm{abcAB}$ & $19 \mathrm{a}$ \\
\hline $45^{\circ} \mathrm{C} / 90 \mathrm{~min}$ & $5 \mathrm{aA}$ & $21 \mathrm{abcA}$ & $23 \mathrm{bcA}$ & $19 \mathrm{ab}$ \\
\hline $55^{\circ} \mathrm{C} / 30 \mathrm{~min}$ & $5 \mathrm{aA}$ & $22 \mathrm{abcA}$ & $23 \mathrm{bcA}$ & $20 \mathrm{a}$ \\
\hline $55^{\circ} \mathrm{C} / 90 \mathrm{~min}$ & $0 \mathrm{aA}$ & $5 \mathrm{bcA}$ & $0 \mathrm{cA}$ & $7 \mathrm{abc}$ \\
\hline$-1,5 \mathrm{MPa}$ & $9 \mathrm{aA}$ & $0 \mathrm{cA}$ & $0 \mathrm{cA}$ & $10 \mathrm{abc}$ \\
\hline$-2,5 \mathrm{MPa}$ & $0 \mathrm{aA}$ & $0 \mathrm{cA}$ & $0 \mathrm{cA}$ & $2 \mathrm{bc}$ \\
\hline Captan & $0 \mathrm{aB}$ & $33 \mathrm{abA}$ & $27 \mathrm{abcAB}$ & $0 \mathrm{c}$ \\
\hline \multirow[t]{2}{*}{ Derosal } & $0 \mathrm{aA}$ & $17 \mathrm{abcA}$ & $14 \mathrm{bcA}$ & $0 \mathrm{c}$ \\
\hline & \multicolumn{3}{|c|}{ Cladosporium sp. } & Penicillium sp. \\
\hline Testemunha & $98 \mathrm{aA}$ & $98 \mathrm{aA}$ & $62 \mathrm{abB}$ & $50 \mathrm{bc}$ \\
\hline $35^{\circ} \mathrm{C} / 30 \mathrm{~min}$ & $93 \mathrm{abA}$ & $98 \mathrm{aA}$ & $89 \mathrm{aA}$ & $38 \mathrm{c}$ \\
\hline $35^{\circ} \mathrm{C} / 90 \mathrm{~min}$ & 89 abA & $98 \mathrm{aA}$ & $89 \mathrm{aA}$ & $41 \mathrm{c}$ \\
\hline $45^{\circ} \mathrm{C} / 30 \mathrm{~min}$ & $89 \mathrm{abA}$ & $93 \mathrm{aA}$ & $85 \mathrm{aA}$ & $33 \mathrm{c}$ \\
\hline $45^{\circ} \mathrm{C} / 90 \mathrm{~min}$ & $58 \mathrm{bcA}$ & $44 \mathrm{bcAB}$ & $25 \mathrm{bcB}$ & $39 c$ \\
\hline $55^{\circ} \mathrm{C} / 30 \mathrm{~min}$ & $49 \mathrm{cAB}$ & $64 \mathrm{abA}$ & $33 \mathrm{bcB}$ & $44 \mathrm{c}$ \\
\hline $55^{\circ} \mathrm{C} / 90 \mathrm{~min}$ & $0 \mathrm{dA}$ & $0 \mathrm{dA}$ & $0 \mathrm{cA}$ & $88 \mathrm{a}$ \\
\hline$-1,5 \mathrm{MPa}$ & $98 \mathrm{aA}$ & $11 \mathrm{cdB}$ & $0 \mathrm{cB}$ & $50 \mathrm{bc}$ \\
\hline$-2,5 \mathrm{MPa}$ & $100 \mathrm{aA}$ & $4 \mathrm{~dB}$ & $0 \mathrm{cB}$ & $72 \mathrm{ab}$ \\
\hline Captan & $0 \mathrm{dA}$ & $0 \mathrm{dA}$ & $4 \mathrm{cA}$ & $6 \mathrm{~d}$ \\
\hline Derosal & $0 \mathrm{dA}$ & $4 \mathrm{dA}$ & $7 \mathrm{cA}$ & $5 \mathrm{~d}$ \\
\hline \multicolumn{5}{|c|}{ Pestalotiopsis sp. } \\
\hline Testemunha & $38 \mathrm{abA}$ & $57 \mathrm{aA}$ & 54 abcA & - \\
\hline $35^{\circ} \mathrm{C} / 30 \mathrm{~min}$ & $30 \mathrm{abcB}$ & $58 \mathrm{aA}$ & $35 \mathrm{cdAB}$ & - \\
\hline $35^{\circ} \mathrm{C} / 90 \mathrm{~min}$ & $34 \mathrm{abcA}$ & $58 \mathrm{aA}$ & $42 \mathrm{bcA}$ & - \\
\hline $45^{\circ} \mathrm{C} / 30 \mathrm{~min}$ & $35 \mathrm{abB}$ & $70 \mathrm{aA}$ & $47 \mathrm{abcAB}$ & - \\
\hline $45^{\circ} \mathrm{C} / 90 \mathrm{~min}$ & $55 \mathrm{aA}$ & $71 \mathrm{aA}$ & $63 \mathrm{abcA}$ & - \\
\hline $55^{\circ} \mathrm{C} / 30 \mathrm{~min}$ & $39 \mathrm{abB}$ & $66 \mathrm{aA}$ & $71 \mathrm{abA}$ & - \\
\hline $55^{\circ} \mathrm{C} / 90 \mathrm{~min}$ & $24 \mathrm{abcB}$ & $71 \mathrm{aA}$ & $78 \mathrm{aA}$ & - \\
\hline$-1,5 \mathrm{MPa}$ & $19 \mathrm{bcA}$ & $0 \mathrm{bA}$ & $0 \mathrm{eA}$ & - \\
\hline$-2,5 \mathrm{MPa}$ & $21 \mathrm{abcA}$ & $0 \mathrm{bA}$ & $5 \mathrm{deA}$ & - \\
\hline Captan & $12 \mathrm{bcA}$ & $10 \mathrm{bA}$ & $0 \mathrm{eA}$ & - \\
\hline Derosal & $0 \mathrm{cA}$ & $0 \mathrm{bA}$ & $0 \mathrm{eA}$ & - \\
\hline
\end{tabular}

Médias seguidas pela mesma letra (minúsculas nas colunas, maiúsculas nas linhas) não diferem entre si (Tukey, 5\%). *Fusarium sp. e Penicillium sp. não apresentaram interação entre tratamentos e períodos de armazenamento. 
A redução e controle dessa incidência fúngica por meio de fungicidas, embora eficiente pode não ser aplicável a espécies utilizadas para restauração vegetal. Os tratamentos térmicos e osmóticos mostraram-se potencialmente interessantes, mas necessitam maiores estudos pois, como verificado no presente trabalho, alguns fungos foram controlados mas não se verificou constância na eficiência dos tratamentos, já que esses não persistem nas sementes como os químicos, pois não apresentam efeito residual. Além disso, o comportamento germinativo e a sanidade das sementes tratadas térmico e osmoticamente foram diferentes, sugerindo que a associação destes tratamentos pode ser favorável, bem como a redução do período de exposição das sementes nas soluções osmóticas e a reaplicação dos tratamentos ao longo do período de armazenamento. Os tratamentos osmóticos utilizados no presente trabalho basearam-se na manutenção das sementes em solução de PEG durante todo o armazenamento, o que prejudicou a manutenção da capacidade germinativa. No entanto, é possível que o controle exercido pelos tratamentos osmóticos sobre a incidência dos fungos não necessite exposição tão prolongada. Assim, tratamentos osmóticos por curtos períodos e repetidos ao longo do armazenamento das sementes podem trazer importante contribuição à conservação desse patrimônio nativo.

\section{CONCLUSÕES}

A redução do teor de água de sementes de grumixameira, pitangueira e uvaieira, principalmente quando associada à aplicação inicial de fungicidas, pode controlar o desenvolvimento de alguns fungos associados a essas sementes; contudo, esse controle não garante ampliação do período de viabilidade das sementes em armazenamento. Além disso, tratamentos alternativos ao químico, como térmicos e osmóticos, podem controlar fungos associados àquelas sementes e, consequentemente, ampliar a capacidade de armazenamento, mas há necessidade de estudos mais específicos.

\section{AGRADECIMENTOS}

Os autores agradecem ao $\mathrm{CNPq}$ pelas bolsas de iniciação científica, concedidas a D.C. Oliveira e C.F. Oliveira e de produtividade, concedida a C.J. Barbedo e pelo auxílio financeiro ao projeto (Proc. 477640/2009-5 e 308045/2007-6), à FAPESP, pelo auxílio financeiro ao projeto (Proc. 2005/04139-7) e ao Jardim Botânico de São Paulo, pela permissão para as coletas das sementes.

\section{REFERÊNCIAS}

ANDRÉO, Y.; NAKAGAWA, J.; BARBEDO, C.J. Mobilização de água e conservação da viabilidade de embriões de sementes recalcitrantes de ingá (Inga vera Willd. subsp. affinis (DC.) T. D. Pennington). Revista Brasileira de Botânica, v.29, p.309-318, 2006. http:// www.scielo.br/pdf/rbb/v29n2/a12v29n2.pdf

ANDRADE, R.N.B.; FERREIRA, A.G. Germinação e armazenamento de sementes de uvaia (Eugenia pyriformis Camb.) - Myrtaceae. Revista Brasileira de Sementes, v.22, p.118-125, 2000. http://www.abrates.org.br/revista/ artigos/2000/v22n2/artigo16.pdf

ANGELOVICI, R.; GALILI, G.; FERNIER, A.R.; FAIT, A. Seed desiccation: a bridge between maturation and germination. Trends in Plant Science, v.15, p.211-218, 2010 .

BARBEDO, C.J.; BILIA, D.A.C. Evolution of research on recalcitrant seeds. Scientia Agricola, v.55, p.121-125, 1998. http://www.scielo.br/pdf/sa/v55nspe/3161.pdf

BARBEDO, C.J.; MARCOS FILHO, J. Tolerância à dessecação de sementes. Acta Botanica Brasilica, v.12, p.145-164, 1998.

BILIA, D.A.C.; MARCOS FILHO, J.; NOVEMBRE, A.D.C.L. Desiccation tolerance and seed storability of Inga uruguensis (Hook. et Arn.). Seed Science and Technology, v.27, p.77-89, 1999.

BRASIL. Ministério da Agricultura e Reforma Agrária. Secretaria Nacional de Defesa Agropecuária. Departamento Nacional de Produção Vegetal. Coordenação de Laboratório Vegetal. Regras para análise de sementes. Brasília, DF, 1992. 365p.

BARNETT, H.L.; HUNTER, B.B. Illustrated genera of imperfectfungi. 4.ed. St. Paul: American Phytopathological Society, 1999. 218p.

CASTELLANI, E.D.; SILVA, A.; BARRETO, M.; AGUIAR, I.B. Influência do tratamento químico na população de fungos e na germinação de Bauhinia variegata L. var. variegata. Revista Brasileira de Sementes, v.18, p.41-44, 1996. http://www.abrates.org.br/revista/ artigos/1996/v18n1/artigo07.pdf 
DECAGON. WP4 Dewpoint PotentaMeter Operator's Manual. Pullman: Decagon Devices, Inc., 2001.

DELGADO, L.F. Tolerância à dessecação em sementes de espécies brasileiras de Eugenia. 2006. 106f. Dissertação (Mestradoe, em Biodiversidade Vegetal e Meio Ambiente) Instituto de Botânica da Secretaria do Meio Ambiente, São Paulo, 2006.

DELGADO, L.F.; BARBEDO, C.J. Tolerância à dessecação de sementes de espécies de Eugenia. Pesquisa Agropecuária Brasileira, v.42, p.265-272, 2007. http:// www.scielo.br/pdf/pab/v42n2/16.pdf

DONADIO, L.C. Study of some Brazilian Myrtaceae in Jaboticabal, SP. Acta Horticulturae, v.452, p.181-183, 1997.

ISTA. International Seed Testing Association. International rules for seed testing. Seed Science and Technology, v.13, p.356-513, 1985.

KOHAMA, S.; MALUF, A.M.; BILIA, D.A.C.; BARBEDO, C.J. Secagem e armazenamento de sementes de Eugenia brasiliensis Lam. (grumixameira). Revista Brasileira de Sementes, v.28, p.72-78, 2006. http://www. scielo.br/pdf/rbs/v28n1/a10v28n1.pdf

KRUGNER, T.L.; AUER, C.G. Doenças dos Eucaliptos. In: KIMATI, H.; AMORIM, L.; REZENDE, J.A.M.; BERGAMIN, A.F.; CAMARGO, L.E.A. (Ed.). Manual de Fitopatologia: doenças das plantas cultivadas. v.2. Piracicaba: Ceres, 2005. p.319-332.

LORENZI, H. Árvores brasileiras: manual de identificação e cultivo de plantas arbóreas nativas do Brasil. Nova Odessa: Plantarum, 1992. 352p.

MACHADO, J.C. Patologia de sementes: fundamentos e aplicações. Brasília: MEC/ESAL-FAEPE, 1988. 106p.

MARCOS FILHO, J. Fisiologia de sementes de plantas cultivadas. Piracicaba: FEALQ, 2005. 495p.

MASUM, M.M.I.; ISLAM, S.M.M.; FAKIR, M.G.A. Effect of seed treatment practices in controlling of seedborne fungi in sorghum. Scientific Research and Essay, v.4, p.22-27, 2009.

MENDES, M.A.S.; LIMA, P.M.M.P.; FONSECA, J.N.L.;
SANTOS, M.F. Erradicação de Fusarium oxysporum em sementes de alfafa utilizando termo e quimioterapia. Fitopatologia Brasileira, v.26, p.148-152, 2001. http:// www.scielo.br/pdf/fb/v26n2/a05v26n2.pdf

MENTEN, J.O.M. Patógenos em sementes: deteç̧ão, danos e controle químico. Piracicaba: ESALQ/FEALQ, 1991.

MICHEL, B.E; KAUFMANN, M.R. The osmotic potential of polyethylene glicol 6000. Plant Physiology, v.51, p.914916, 1973.

NASCIMENTO, W.M.O.; CRUZ, E.D.; MORAES, M.H.D.; MENTEN, J.O.M. Qualidade sanitária e germinação de sementes de Pterogyne nitens Tull. (Leguminosae - Caesalpinioideae). Revista Brasileira de Sementes, v.28, p.149-153, 2006. http://www.scielo.br/ $\mathrm{pdf} / \mathrm{rbs} / \mathrm{v} 28 \mathrm{n} 1 / \mathrm{a} 21 \mathrm{v} 28 \mathrm{n} 1 . \mathrm{pdf}$

NAMETH, S.T. Priorities in seed pathology research. Scientia Agricola, v.55, p.94-97, 1998. http://www.scielo. br/pdf/sa/v55nspe/3156.pdf

NETTO, D.A.M.; FAIAD, M.G.R. Viabilidade e sanidade de sementes de espécies florestais. Revista Brasileira de Sementes, v.17, p.75-80, 1995. http://www.abrates.org.br/ revista/artigos/1995/v17n1/artigo13.pdf

ROBERTS, E.H. Predicting the storage life of seed. Seed Science and Technology, v.1, p.499-514, 1973.

SANTANA, D.G.; RANAL, M.A. Análise da germinação: um enfoque estatístico. Brasília: UnB, 2004. 248p.

SILVA, C.V.; BILIA, D.A.C.; MALUF, A.M.; BARBEDO, C.J. Fracionamento e germinação de sementes de uvaia (Eugenia pyriformis Cambess.- Myrtaceae). Revista Brasileira de Botânica, v.26, p.213-221, 2003. http:// www.scielo.br/pdf/rbb/v26n2/a09v26n2.pdf

VIEIRA, A.H.; MARTINS, E.P.; PEQUENO, P.L.L.; LOCATELLI, M.; SOUZA, M.G. Técnicas de produção de sementes florestais. CT/205, EMBRAPA-CPAF, Rondônia. p.2-4, 2001.

VON BÜLOW, J.F.W.; CARMONA, R.; PARENTE, T.V. Armazenamento e tratamento de sementes de pitangavermelha-do-cerrado (Eugenia calycina). Pesquisa Agropecuária Brasileira, v.29, p.961-970, 1994. http:// webnotes.sct.embrapa.br/pab/pab.nsf/FrAnual 